\title{
Review of Orbiter Flight Boundary Layer Transition Data
}

\author{
Catherine B. McGinley ${ }^{*}$ and Scott A. Berry. ${ }^{\dagger}$ \\ NASA Langley Research Center, Hampton, VA, 23681 \\ Gerald R. Kinder ${ }^{\ddagger}$ \\ The Boeing Company, Huntington Beach, CA, 91745 \\ Maria Barnwell ${ }^{\S}$ and Kuo C. Wang ${ }^{* *}$ \\ The Boeing Company, Houston, TX, 77059 \\ and \\ Benjamin S. Kirk ${ }^{\dagger}$ \\ NASA Johnson Space Center, Houston, TX, 77058
}

\begin{abstract}
In support of the Shuttle Return to Flight program, a tool was developed to predict when boundary layer transition would occur on the lower surface of the orbiter during reentry due to the presence of protuberances and cavities in the thermal protection system. This predictive tool was developed based on extensive wind tunnel tests conducted after the loss of the Space Shuttle Columbia. Recognizing that wind tunnels cannot simulate the exact conditions an orbiter encounters as it re-enters the atmosphere, a preliminary attempt was made to use the documented flight related damage and the orbiter transition times, as deduced from flight instrumentation, to calibrate the predictive tool. After flight STS-114, the Boundary Layer Transition Team decided that a more in-depth analysis of the historical flight data was needed to better determine the root causes of the occasional early transition times of some of the past shuttle flights. In this paper we discuss our methodology for the analysis, the various sources of shuttle damage information, the analysis of the flight thermocouple data, and how the results compare to the Boundary Layer Transition prediction tool designed for Return to Flight.
\end{abstract}

\section{Nomenclature}

$=$ cavity depth

$=$ protrusion height

$=$ cavity length

$=$ boundary layer edge Mach number

$=$ orbiter Mach number

$=$ orbiter vehicle

$=$ momentum thickness Reynolds number, $\rho_{\mathrm{e}} \mathrm{U}_{\mathrm{e}} \theta / \mu_{\mathrm{e}}$

$=$ space transportation system

$=$ boundary layer edge velocity

$=$ time from entry interface

$=$ cavity width

$=$ longitudinal axis

\footnotetext{
${ }^{\dagger}$ Aerospace Engineer, Aerothermodynamics Branch, MS 408A

* Entry Aeroheating Analyst, Thermal Systems, MC H012-C248

$\S$ Engineering Analyst, Orbiter Aeroheating Analysis

${ }^{* *}$ Engineer/Scientist 5, Integrated Defense System

${ }^{\dagger}$ Aerospace Engineer, Applied Aerosciences \&CFD Branch
}

${ }^{*}$ Aerospace Engineer, Flow Physics and Control Branch, MS 170, member AIAA 


$\begin{array}{ll}Y & =\text { spanwise axis } \\ Z & =\text { vertical axis } \\ \alpha & =\text { angle of attack } \\ \delta & =\text { boundary layer thickness } \\ \mu_{\mathrm{e}} & =\text { viscosity } \\ \rho_{\mathrm{e}} & =\text { boundary layer edge density }\end{array}$

\section{Introduction}

One of the recommendations of the Columbia Accident Investigation Board (CAIB) was to "develop, validate, and maintain physics-based computer models to evaluate Thermal Protection System damage from debris impacts."1 Upon re-entry into the atmosphere, a space shuttle with no significant damage to its Thermal Protection System (TPS) will generally experience boundary layer transition from laminar to turbulent flow at an elapsed time after entry interface $\mathrm{t}>1200 \mathrm{~s}$ at $\mathrm{M}_{\infty} \leq 8$. Transition times this late in the trajectory are considered nominal as the vehicle was designed to safely handle the additional turbulent heat load. Damages to the lower surface of the orbiter, in the form of protruding gap fillers or cavities formed due to damage incurred during ascent, are capable of triggering transition at times earlier than would occur for natural transition. When transition occurs earlier in the reentry phase and therefore at higher Mach numbers, the shuttle may be exposed to unacceptable heating rates. Furthermore, if transition occurs asymmetrically the orbiter may experience unexpected rolling and yawing moments that require correction by the Reaction Control System (RCS). ${ }^{2}$ Since the orbiters have a limited amount of propellant available for vehicle maneuvering it is important to be able to predict the likelihood of asymmetric transition.

Research regarding the aero heating environment at hypersonic flight conditions, with its associated impact on the vehicle thermal protection system, began early in the design process of the Orbiter vehicle ${ }^{3}$. For the initial five flights of the Space Shuttle, an extensive set of thermocouples was used to acquire temperature data on the surface of the orbiter Columbia (OV-102) during reentry. Several authors have analyzed the data from these flights to validate designs assumptions. For an initial review of the flight heating results, see Lee and Harthun. ${ }^{4}$ Further reviews $5,6,7$ of the early flight data (including the first five flights), along with a discussion of the times that boundary layer transition occurred, were first provided at the Shuttle Performance Lessons Learned Conference held at NASA Langley Research Center in 1983. Additional analyses of these early orbiter flight transition results continued and were reported by Poll ${ }^{8}$ and Hartung and Throckmorton. ${ }^{9,10}$ After STS-5 no data were recorded for the surface thermocouples until STS-26, the first flight after the loss of the Challenger (OV-99). The Orbiter Experiments (OEX) Aerothermodynamics Symposium ${ }^{11}$ in 1993 provided further review of Shuttle flight transition results, now based on over fifty flights. At about this same time, the Orbiter Boundary-Layer Transition Working Group ${ }^{12}$ was formed by the NASA Johnson Space Center to study the impact of early and/or asymmetric transition on the Shuttle program. They found that over half of the early transition cases would likely be asymmetric. Bouslog et al. ${ }^{13}$ provides additional flight results (including two of the very early transition flight cases, STS-28 and 73) with comparison to ground-based data.

The ability to predict transition onset times based on observable damage became a necessary tool (as one part of a suite of tools ${ }^{14}$ to assess the overall health of the TPS) to have before the shuttle could return to flight. As part of the Return to Flight (RTF) effort that evolved after the loss of the space shuttle Columbia and in response to the CAIB report, a Boundary Layer Transition (BLT) team was formed to develop a tool to predict the onset of boundary layer transition on the windward side of the orbiter during reentry. Berry et al. ${ }^{15}$ provides a review of the effort, in support of the return to flight of STS-114, to develop the BLT Tool to predict the effects of damage encountered in flight on the time of transition. Building on research conducted during the investigation into the loss of STS-107, the BLT team conducted several wind tunnel tests of the effects of protuberances and cavities on transition. ${ }^{16}$ Greene et al. ${ }^{17}$ provides the details of the computational method used and the database interpolation tool developed to provide the boundary layer properties at both wind tunnel and flight conditions. Additionally, as a companion to the BLT Tool for predicting the time of transition, a graphical tool for identifying the turbulent spreading influence from each damage site was developed prior to STS-114 called the Wedge Tool. In order to validate the tools developed to support flight STS-114, several orbiter flights that encountered early transition were analyzed and compared to wind tunnel data. Specifically, data from flights STS-28R, 55, 73, 81, 94, 99, and 103 were examined for boundary layer transition due to protruding gap fillers and STS-1, 41, 89, 104, and 111 were examined for transition due to cavities. After the successful flight of STS-114, the team decided the flight data should be reanalyzed with the hope of finding additional sources of information not available prior to STS-114. Furthermore, it was decided that all shuttle flights should be documented for damage to the TPS on the lower 
surface and that damage should be quantified and analyzed for its effects on transition. In this paper, we discuss the methodology that will be used in this reanalysis and present the results for five flight cases, STS-28R, STS-55, STS99, STS-1, and STS-41.

\section{Analysis}

For our reanalysis of the flight data with regard to transition we have adopted the following methodology. First, the transition onset times at specific locations are computed from the output of thermocouples located on the lower surface of the vehicle. Next, the orbiter lower surface TPS damage data are obtained from all available sources. Once the damage locations and dimensions have been quantified, the boundary layer properties are obtained and the predicted transition times due to damage are computed using the BLT Tool. Then the Wedge Tool is used to predict the path of the turbulent wedge from an individual damage site to see if it passes over the thermocouples. Finally, the actual transition times and the predicted transition times are compared to help establish cause and effect for transition and to evaluate the predictive capability of the tools.

\section{A. Flight Data}

All flight data were downloaded from the Operational Data Reduction Complex (ODRC). Through the ODRC the thermocouple data were obtained from the Modular Auxiliary Data System (MADS), Pulse Code Modulation Multiplexer 1 (PCM1). (Note, this data source provides the thermocouple data for STS-1 even though for STS-1 through 5 the data were obtained through the Developmental Flight Instrumentation system.) Each orbiter is equipped with thermocouples that record the temperature on the surface of the orbiter. For the first five flights of the space shuttle Columbia, the lower surface was heavily instrumented with thermocouples. For the post Challenger flights, the lower surface temperatures from a very limited number of widely spaced thermocouples were recorded for all of the orbiters (barring equipment malfunctions).

The surface thermocouple measurements were used to determine the time that the flow transitioned from laminar to turbulent at a specific location on the lower surface of the orbiters. As the boundary layer begins the transition process the heat transfer to the surface increases rapidly, thus increasing the temperature that the thermocouple senses. After the flow turns turbulent the heat transfer rate drops below the peak of transition heating, but remains above the value of laminar heating. Of course, for a vehicle reentering the atmosphere, the conditions are constantly changing and the temperature is also affected by vehicle maneuvers and atmospheric conditions.

The flight parameters such as vehicle Mach number, angle of attack, and roll angle were obtained from the OD (shuttle data) and BET (best estimated trajectory) databases of the ODRC. The data source that we used for the orbiter vehicle Mach number is listed as the "Nav derived Mach number" from the OD database.

\section{A. Sources of Damage Information}

Early transition on the lower surface of the orbiter is generally considered to be caused by protruding gap fillers or by cavities created by debris impact during the ascent phase. Gap fillers, as seen during the recent shuttle flight STS-1 $14,{ }^{18}$ can become dislodged during ascent and protrude beyond the outer mold line (OML) of the orbiter surface. Prior to STS-114, where on orbit pictures and measurements were obtained, there was no way to know if or to what extent gap fillers were protruding above the surface. As the shuttle returns from orbit, protruding gap fillers encounter extremely high temperatures and can fray and bend. At this point we cannot predict when or if this may occur during reentry. For all flights prior to STS-114, we must base our analysis on the dimensions documented upon landing. For cavities, also measured for the first time in flight during STS-114, the geometries are not expected to change drastically during reentry. Cavities subjected to high reentry temperatures will, however, exhibit melting and glazing. This type of reentry damage can be helpful in distinguishing between cavities existing prior to reentry and those caused after landing. In general, we relied on four sources of information for damage dimensions and locations.

The first source contains reports written for each flight by Boeing (and previously Rockwell) called the Thermal Protection System Post Flight Assessment (for the purposes of this paper these reports will be referred to as TPSPFA). These reports document the condition of the TPS after landing. The assessment contains a discussion of the transition time of the orbiter and any damage that may be related to the transition time and sometimes contains the location and size of the damage. The second source encompasses the Quick Look Runway reports (hereafter QLR) that are written by the runway team that examines the orbiter before it is moved from the runway to the processing facility. These observations are usually, but not always, incorporated into the first source. The third source is generated by the Debris Ice Team at Kennedy Space Center and the reports are written as NASA Technical Memorandum (TM) publications. One of the objectives of the Debris Ice Team reports (hereafter referred to as the 
DIT reports) is to document the damage to the orbiter and to try to discover the cause of the damage. These reports contain sketches of the lower surface of the orbiter and the dimensions (but not the exact locations) of cavities in excess of 1 inch. In the cases of particularly large cavities these reports will sometimes discuss the tile numbers associated with the cavity. The fourth source is the formal computer tracking system for problems and corrections to the entire orbiter.

In searching the computerized tracking system we relied on the KSC IPR/PR/DR search tool and database. This search tool enables us to search the Discrepancy Reports (DR), the Interim Problem Reports (IPR), the Line Replaceable Unit (LRU), the Matrix Discrepancy Report (MDR), the Problem Report (PR), the Tile Discrepancy Report (TDR) and the Tile Problem Report (TPR). The system provides a highly functional search capability. To obtain damage from an individual flight it was found that damage discovered post landing was logged into the system under the flight number associated with the next flight of that same orbiter. For example, to search for information for flight STS-28 of the orbiter Columbia (OV-102) for the search function STS/Element/Effectivity we would select STS-32R/Any/Any. This was verified by comparing the dates of the damage entries with the known landing dates of the orbiters. (Note that we have not verified this for any flight prior to STS-26.) The search was then limited to flight damage by choosing option $\mathrm{P}$ under the Cause menu. The system also gave the ability to search for words in the text and to limit the data by a How Malfunctioned code that contained options such as Gap Filler Damaged/Missing/Incorrect. We found, however, that in many instances damage was entered with no code designation. Therefore, our procedure was to download all of the flight damage (can be over 1500 records), use the tile numbers provided to find the location of the damage, limit the file to damage that only occurred on the lower surface, and then manually sort through the remaining damage to find any size protruding gap fillers and cavities that contained at least one dimension in excess of 1 inch. It is important to note that for this system, the cavity damage was described for each tile separately. Therefore, if a cavity crossed several tiles each part would be listed individually for each tile. Unless a specific note was attached to the entry, it was impossible to tell if a cavity covered more than one tile. We could, however, verify the data from the first three sources by combining damage on tiles that were common to the other reports.

No one source was a consistent provider of all of the damage on a vehicle. For the first three sources, in many instances the physical locations for the damage were not given. When the tile numbers were given the location of the damage was taken as the tile location. For gap fillers, if the tile numbers on either side of the gap filler were given, then the location of the gap filler was taken as being the average of the two locations. For cavities located across more than one tile, we attempted to find a center point for the cavity. Also, the first three reports are not independent observations. For instance, the TPSPFA reports contain maps of the lower surface of the orbiter identical to those provided by the DIT reports, however the size of the damages are not included on the maps and locations of the damages were not given. Some of the earlier reports included listings of the tile number and written descriptions of the damage; however, this information was not included in subsequent reports. When only photographs were provided of the damage, we would attempt to find the tile number and thereby obtain the locations. Tracking tile numbers over the years would prove difficult because damaged tiles are sometimes replaced and renumbered. Fortunately, a historical database of tiles and their locations is maintained by The Boeing Company in support of the Space Shuttle Program.

Aside from these sources, we have sometimes found the need to rely on less formal sources such as internal memos, presentations, or photographs from old files. We have made every effort to document these sources.

\section{A. Prediction tools}

\section{Boundary Layer Transition (BLT) Tool}

The BLT Tool was developed to predict the boundary layer transition as a function of the flight path time. To obtain the necessary boundary layer parameters, e.g., the momentum thickness and the edge Mach number, an interpolation tool was developed that would use the mission specific profile and the results from CFD simulations to determine these parameters at each damage site as a function of the time from entry interface. ${ }^{17}$ After the local boundary layer edge parameters were determined from the interpolation tool, the BLT Tool,

$$
\frac{\operatorname{Re}_{\theta}}{M_{e}} * \frac{k}{\delta}=C
$$

was used to determine the time of transition. The value of the constant $\mathrm{C}$ was determined by numerous wind tunnel studies and was based on a conservative estimate of the time of incipient transition. For protrusions (e.g., gap fillers) $C=27$ and $\mathrm{k}$ is the height of the protrusion. However, it should be pointed out that the value of $C=27$ was 
derived from fitting wind tunnel data obtained on protrusions in the shape of raised tiles, not gap fillers. For cavities, if $k$ is replaced by the cavity depth, $d$, then $C=100$. If $k$ is replaced by the length, $l$, of the cavity then $C=900$. Since the boundary layer interpolation tool provides $\mathrm{Re}_{\theta}, \mathrm{M}_{\mathrm{e}}$, and $\delta$ as functions of time, the transition time is simply the time where the later variables satisfy the equality.

\section{Wedge Tool}

After the damage and the thermocouple data were collected, we needed to predict the path of the turbulent wedge to see if it passed over a thermocouple location. The Wedge Tool makes use of viscous computational fluid dynamics solutions with reacting chemistry (provided by the LAURA ${ }^{19}$ and DPLR ${ }^{20}$ codes) for the flow around the orbiter for specific angles of attack. The flow is assumed to be fully turbulent from the trip location and the wedgespreading half angle is set at $7.5^{\circ}$. The value of $7.5^{\circ}$ was chosen for post flight analysis, however, while using the tool for analysis of damage during an actual flight a conservative value of $10^{\circ}$ is used. The value of $7.5^{\circ}$ used for post flight analysis is larger than the value of approximately $5^{\circ}$, for $\mathrm{M}_{\mathrm{e}} \sim 3$., predicted by Fischer ${ }^{21}$ who compiled turbulence spreading angle data versus Mach number. However, $7.5^{\circ}$ was found to provide better agreement with the observed flight data. By following the streamlines, using the boundary layer edge properties and the wedge half angle, the path of the turbulent wedge is predicted. The Wedge Tool is currently in the process of being baselined through the Orbiter Project Office to be officially sanctioned for use during the on orbit decision-making process.

\section{Flight Cases}

The orbiter coordinate system is show in Fig. 1. Note that the origin for the $\mathrm{X}$ axis begins 236 inches ahead of the nose of the orbiter. For this paper, we will present an analysis of flights STS-28R (Columbia, OV102), STS-55 (Columbia, OV102), STS-99 (Endeavor, OV105), STS-1 (Columbia, OV102), and STS-41 (Discovery, OV103) for the effect of flight damage on transition. For the initial calibration of the BLT Tool prior to flight STS-114, the first three cases were considered protrusion (gap filler) cases and the final two were considered cavity cases. For our present analysis we gathered data on gap fillers and cavities for each flight and analyzed the effects of each on transition. In our discussion below we will first discuss the three cases that were previously considered gap filler cases and then address the two cases that were considered cavities.

\section{A. STS-28R}

STS-28R was the $8^{\text {th }}$ flight of the orbiter Columbia (OV102) and landed at Edwards Air Force Base in California on August 13, 1989. Upon analysis of the thermocouple data, it was noted in the TPSPFA report ${ }^{22}$, that transition occurred much earlier than expected. The thermocouple names and locations on the lower surface of the orbiter Columbia for STS-28R and all flights of Columbia with the exception of STS-1 through STS-5 are shown in Fig. 2. The data from select thermocouples are shown in Fig. 3. The trace for thermocouple V07T9674A, located on the aft portion of the left wing, show the classic sign of transition by the rapid rise in temperature as the flow switches from laminar to turbulent. Thermocouples V07T9468A and V07T9470A both show what is considered to be close to

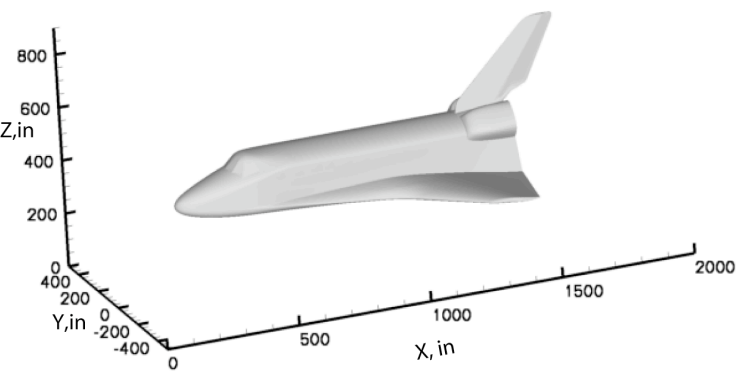

Figure 1. Space shuttle coordinate system. natural transition, occurring at an elapsed time from entry interface greater than $1200 \mathrm{sec}$. Thermocouple V07T9478A shows a peculiar response where it appears to transition, then the temperature drops, only to rise again. For our analysis, we choose the initial rise as the onset of transition. Our reasoning behind this was twofold; first the earlier transition time is similar to the transition time on V07T9674A that transitioned cleanly and second because it was considered the more conservative estimate. Sensors V07T9480A and V07T9666A, not shown in the figure, also exhibited odd behavior during the same time period. Previous researchers ${ }^{23,24}$ have suggested that this may be the result of angle of attack, $\alpha$, variations. STS-28R did experience an $\alpha$ variation during the time period indicated. Between $854 \mathrm{~s}<\mathrm{t}<872 \mathrm{~s} \alpha$ increased by approximately 2.6 degrees. From $872 \mathrm{~s}<\mathrm{t}<930 \mathrm{~s}, \quad \alpha$ decreased 2.4 degrees. Three more smaller $\alpha$ variations occurred until $\mathrm{t} \sim$ 1172s. These slow oscillations begin approximately 48 seconds prior to the transitions times shown in Fig. 3. The orbiter is also performing roll maneuvers during this time. At $\mathrm{t} \sim 827 \mathrm{~s}$ a roll maneuver begins and completes at $\mathrm{t}$ $\sim 862 \mathrm{~s}$. At $\mathrm{t} \sim 995 \mathrm{~s}$ the roll rate changes sign and this occurs at approximately the same time as the sudden drop in the temperature reading on V07T9478A. Such vehicle maneuvers will not only change the boundary layer, but will 
change the path of the streamlines emanating from the protrusion/damage sites. At this point, the relationship between the orbiter flight parameters and the output of the thermocouples is not clear. In other words, transition can affect the flight of the vehicle and the flight of the vehicle can affect the state of transition.

After the early transition times were identified, it was decided that the most probable cause for the transition was several gap fillers that were found to be protruding from the OML of the orbiter. The TPSPFA report ${ }^{22}$ listed the surrounding tile numbers of two gap fillers located forward on the lower TPS. There was no mention the protrusion height of the gap fillers in the report. The DIT report ${ }^{25}$ prepared by the Debris Ice Team mentions three protruding gap fillers located on the lower surface with only one located on the forward fuselage. It also provides the approximate locations of the gap fillers, but no quantitative values. A search of the KSC IPR/PR/DR database verified the locations of the two aft gap fillers. In 2004 Kinder prepared a memo ${ }^{26}$ for the Boeing Company in which he addressed the confusion over the location and protrusion height of the gap fillers for various internal reports on flight STS-28R. In the Kinder memo and the KSC IPR/PR/DR database there are also references to the gap fillers being bent over, but again no quantitative values are provided. In all we found 10 protruding gap fillers and 27 cavities with dimensions greater than 1 in.

Using the BLT tool we analyzed all of the gap fillers and cavities and determined that the three gap fillers noted in the TPSPFA report and Kinder memo were the likely source of early boundary layer transition on the orbiter. The locations and dimensions of the gap fillers are detailed in Table 1. The location of the gap fillers on the orbiter surface and the paths of the streamlines as predicted by the Wedge Tool are shown in Fig. 4. Also included in the figure are the thermocouple locations and transition times as determined from each thermocouple. The resulting transitional wedge emanating from gap filler A_28 is not predicted to have affected the first two thermocouples and this is consistent with the later transition times predicted by those thermocouples. Gap filler B_28 is shown to influence three downstream thermocouples and the resulting wedge is predicted to contaminate the leading edge of the orbiter. The final gap filler, C_28, did not influence any of the surface thermocouples. Using the BLT Tool, we computed the expected transition time using the correlation established by the wind tunnel tests and approved for use for Return to Flight. The times and the associated Mach numbers are listed in Table 2. In this case, the BLT Tool predicted transition earlier than occurred on the vehicle.

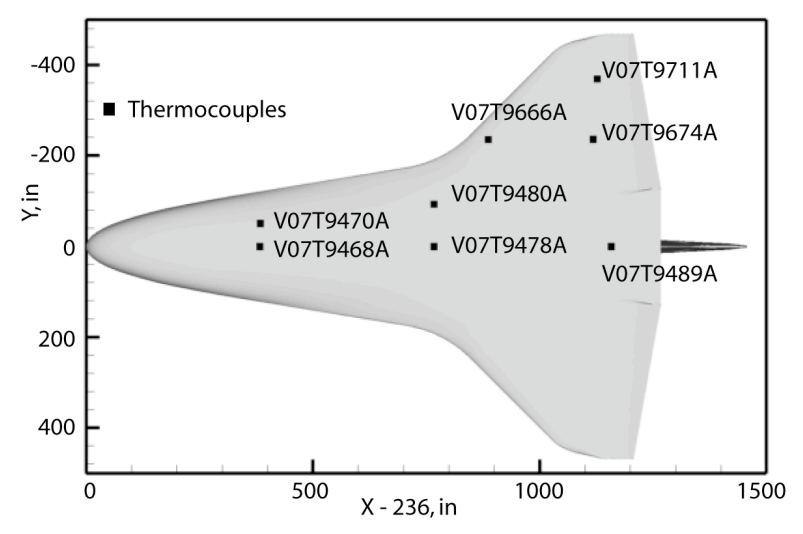
Columbia (STS-28 and STS-55).

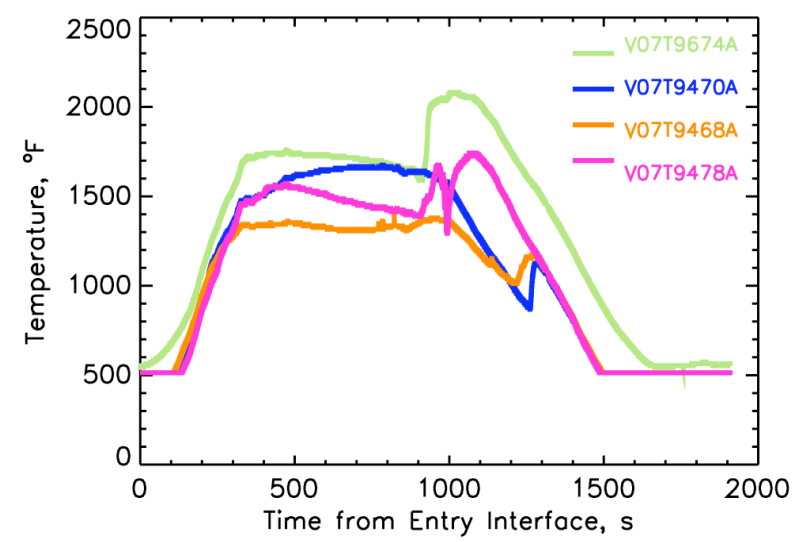

Figure 3. Thermocouple traces for STS-28R.

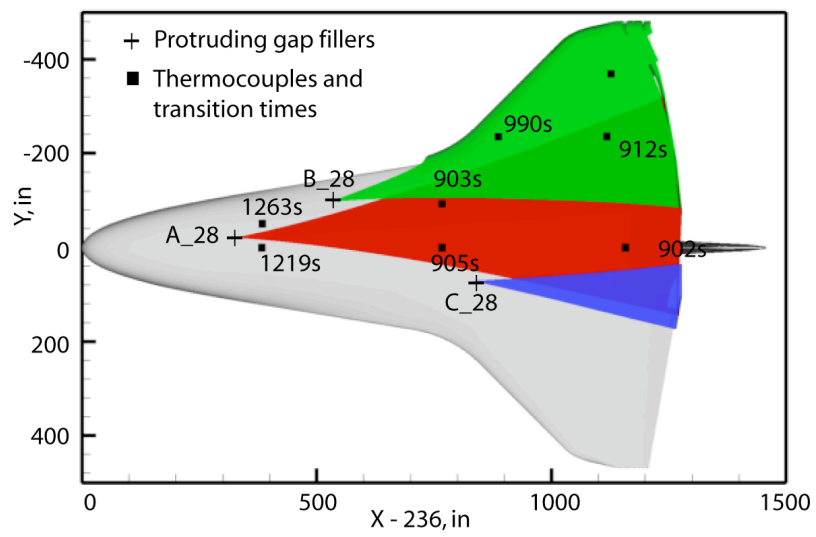

Figure 4. STS-28 Thermocouple transition times and predicted paths of turbulent wedges from damage sites.
Figure 2. Thermocouple names and locations for 
Table 1. STS-28 Gap filler locations.

\begin{tabular}{|c|c||c|c|c||c||}
\hline Gap Filler & X-236., in & Y, in & Z, in & k, in & Source \\
\hline \hline A_28 & 329. & -21. & 278. & 0.5 & Ref. 25 \\
\hline \hline B_28 & 528. & -94. & 282. & 0.5 & Ref. 25 \\
\hline \hline C_28 & 832. & 70. & 268. & 0.5 & Ref. 25 \\
\hline
\end{tabular}

Table 2. STS-28 transition time comparisons

\begin{tabular}{|l||l||l|l||l||}
\hline & $\begin{array}{l}\text { Actual } \\
\text { Predicted } \\
\text { Transition } \\
\text { Time, s (BLT Tool) }\end{array}$ & $\begin{array}{l}\text { Transition } \\
\text { Time, } s \\
\text { (Thermocouple) }\end{array}$ & $\begin{array}{l}\text { Actual } \\
\text { Predicted } \\
\text { Mach Number } \\
\text { (BLT Tool) }\end{array}$ & $\begin{array}{l}\text { Transition } \\
\text { Mach Number } \\
\text { (Nav) }\end{array}$ \\
\hline Aa28 Filler & 864. & 905. & 18.6 & 17.8 \\
\hline B_28 & 827. & 903. & 19.4 & 17.9 \\
\hline C_28 & 803. & N/A & 20.0 & N/A \\
\hline
\end{tabular}

\section{B. STS-55}

STS-55, was the $14^{\text {th }}$ flight of the orbiter Columbia (OV102) and landed at Edwards Air Force Base in California on May 6, 1993. The time histories of four of the thermocouples for this flight are shown in Fig. 5. The thermocouples show signs of early transition all at approximately the same time. The temperature signals for sensors V07T9468A and V07T9478A show an initial rise followed by a short decline and then rise again. The peak coincides with a roll rate sign reversal as in STS28 , however this flight experienced other roll rate sign reversals that did not coincide with similar effects on the thermocouple traces.

For this flight the TPSPFA ${ }^{27}$ report documented five protruding gap fillers. The numbers for the surrounding tiles for the gap fillers were given in the report but no dimensions were listed. In this instance, information from the KSC IPR/PR/DR database concurred with the locations provided in the TPSPFA report and provided the protrusion height information for four of the gap fillers. Overall, we were able to locate 20 gap fillers and 20 cavities on the lower surface. In one instance we had to rely on the QLR report for a gap filler height.

All of the gap fillers and cavities were analyzed using equation 1 of the BLT Tool. The five gap fillers noted in the TPSPFA reports were found to be the likely cause of the early transition. The locations and heights are presented in Table 3. The paths of the streamlines emanating from the five gap fillers determined to have a significant influence on transition are plotted in Fig. 6. In this case, the results from the Wedge Tool predict that gap fillers A_55, B_55, and C_55 affected the temperatures sensed by the all of the thermocouples. The paths emanating from D_55 and E_55 do not affect any thermocouples. The predicted transition times for the gap fillers are compared to the actual time of transition in Table 4. Transition for all three gap fillers was assumed as starting at $\mathrm{t}=1060 \mathrm{~s}$, the earliest transition time, since their paths were predicted to pass over all of the thermocouples. Two of the gap fillers, A_55 and

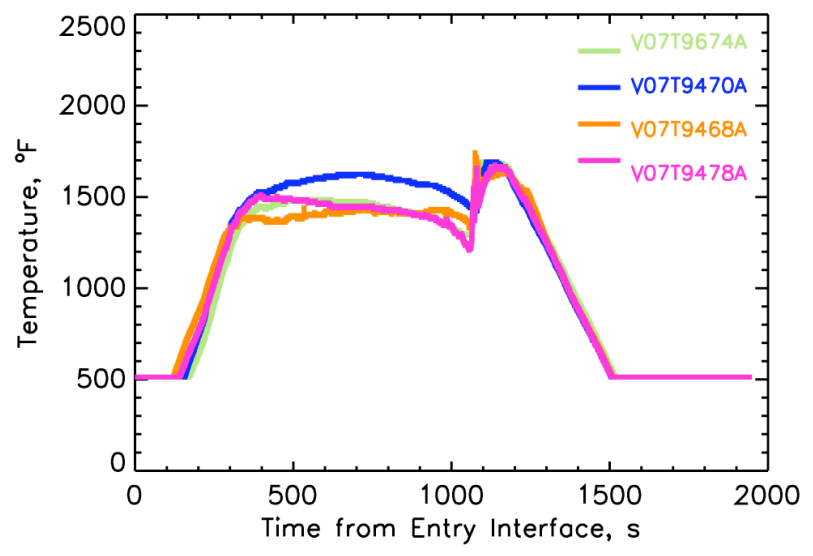

Figure 5. Thermocouple traces for STS-55.

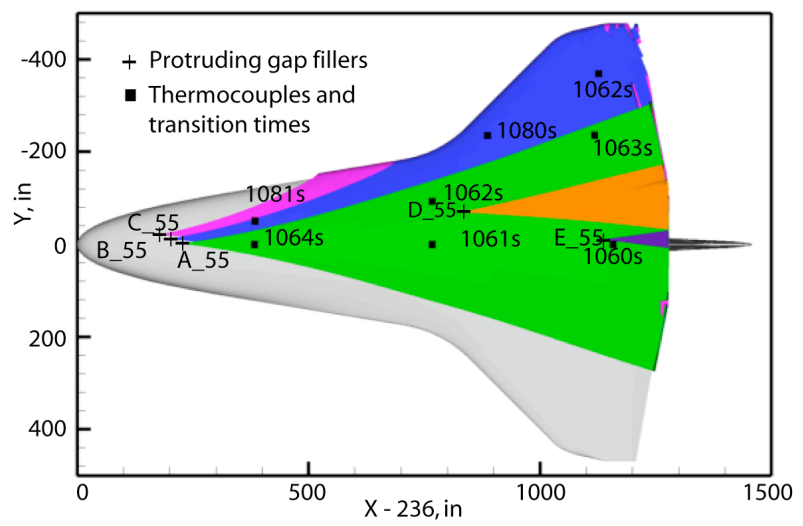

Figure 6. STS-55 Thermocouple transition times and predicted paths of turbulent wedges from damage sites.

7

American Institute of Aeronautics and Astronautics 
C_55, were predicted to cause transition before the time computed from the thermocouple traces and one, B_55, was predicted to cause transition after. Since transition would have occurred due to A_55 and C_55 before B_55, we can only truly compare the predicted values of A_55 and C_55 with the actual transition times. The predicted versus actual transition times for this case compare slightly better them STS-28R. This may be due to more reliable measurements of the gap filler protrusion heights. Transition for gap fillers D_55 and E_55 occurred before the predicted transition times but due to the widely spaced nature of the thermocouples their influence was not detected.

Table 3. STS-55 Gap filler locations.

\begin{tabular}{|c|c|c|c|c|c|}
\hline Gap Filler & $\mathrm{X}-236 .$, in & $\mathrm{Y}$, in & $Z$, in & Height, in & Source \\
\hline A_55 & 225.1 & -2.1 & 278.0 & 0.2 & KSC IPR/PR/DR \\
\hline B_55 & 198.6 & -11.7 & 281.5 & 0.15 & KSC IPR/PR/DR \\
\hline C 55 & 181.6 & -20.2 & 282.9 & 0.2 & KSC IPR/PR/DR \\
\hline D_55 & 828.6 & -68.9 & 268.0 & 0.2 & QLR \\
\hline E 55 & 1137.3 & -10.6 & 262.8 & 0.5 & KSC IPR/PR/DR \\
\hline
\end{tabular}

Table 4. STS-55 Comparison of transition times.

\begin{tabular}{|c|c|c|c|c|}
\hline Gap Filler & $\begin{array}{l}\text { Predicted } \\
\text { Transition } \\
\text { Time, s (BLT Tool) }\end{array}$ & $\begin{array}{l}\text { Actual } \\
\text { Transition } \\
\text { Time,s } \\
\text { (Thermocouple) } \\
\end{array}$ & $\begin{array}{l}\text { Predicted } \\
\text { Mach Number } \\
\text { (BLT Tool) }\end{array}$ & \begin{tabular}{|l} 
Actual \\
Transition \\
Mach Number \\
(Nav)
\end{tabular} \\
\hline A 55 & 1036. & 1060. & 13.9 & 14.0 \\
\hline B_55 & 1074. & 1060. & 12.6 & 14.0 \\
\hline C 55 & 1032. & 1060. & 14.0 & 14.0 \\
\hline D_55 & 979. & N/A & 15.6 & N/A \\
\hline E_55 & 834. & N/A & 19.1 & N/A \\
\hline
\end{tabular}

\section{STS-99}

STS-99, was the $14^{\text {th }}$ flight of the orbiter Endeavor (OV105) and landed at Kennedy Space Center in Florida on February 22, 2000. The orbiter Endeavor has a different arrangement of thermocouples as seen in Fig. 7. The thermocouples are arranged in a symmetric pattern on either side of the orbiter centerline and thus can be used to detect asymmetrical transition. The traces for four of the thermocouples are shown in Fig. 8. Early transition occurred on thermocouples V07T9590A, V07T9489A, and V07T9480A. At V07T9470A, located on the forward lower surface, the signal indicates the typical vehicle transition time associated with no debris damage.

One gap filler was noted as protruding from the lower surface by the TPSPFA report ${ }^{28}$ and a protrusion height was given. We verified the location of the gap filler with data from the KSC IPR/PR/DR database, but no height information was found. The height of the gap filler was listed as 0.35 in tapering to $0.25 \mathrm{in}$. For the purposes of our investigation we used the maximum height to compute the transition time. From the KSC IPR/PR/DR database 22 cavity sites were found on the lower surface of the orbiter. The location and dimension of the gap filler are listed in Table 6.

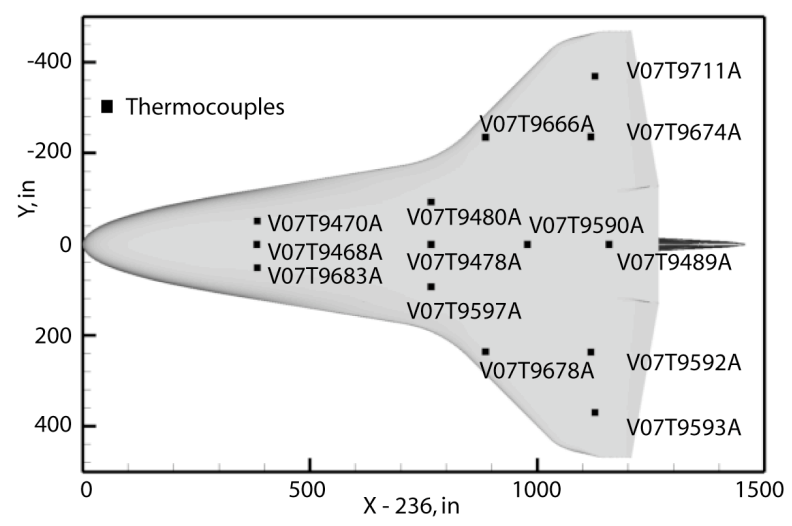

Figure 7. Thermocouple names and locations for Endeavor.

8

American Institute of Aeronautics and Astronautics 
The gap filler and cavities were analyzed using Eq. 1 from the BLT Tool. The lone gap filler was found to be the likely source of transition. The location of the gap filler is listed in Table 5. The extent of the expected influence of the lone gap filler as predicted by the Wedge Tool is seen in Fig. 9. The path projected by the Wedge Tool accounts for the locations where the data from the thermocouples indicated early transition. Along the centerline it appears that transition occurred at approximately the same time over a significant portion of the vehicle's length. For thermocouples outside the region of influence of the gap filler, transition occurs first on the aft end of the vehicle and then moves forward in time. A comparison of the predicted transition times and Mach numbers is shown is Table 6. There is good agreement between the values predicted by Eq. 1 and the transition times computed from the thermocouple data.

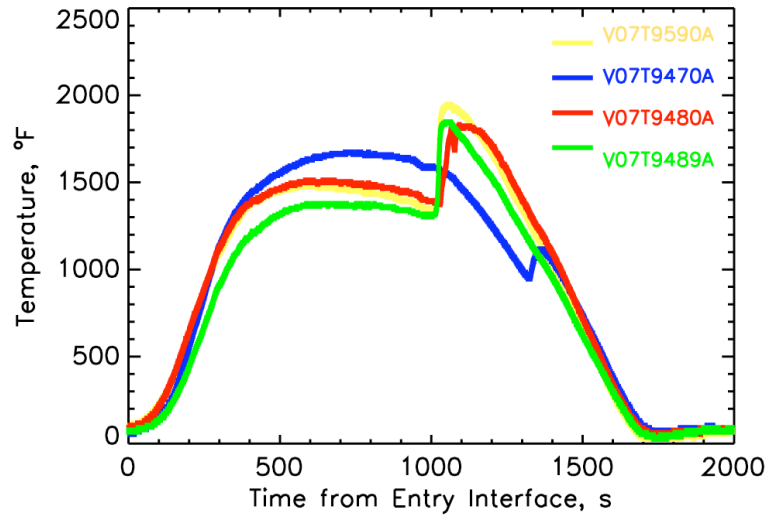

Figure 8. Thermocouple traces for STS-99.

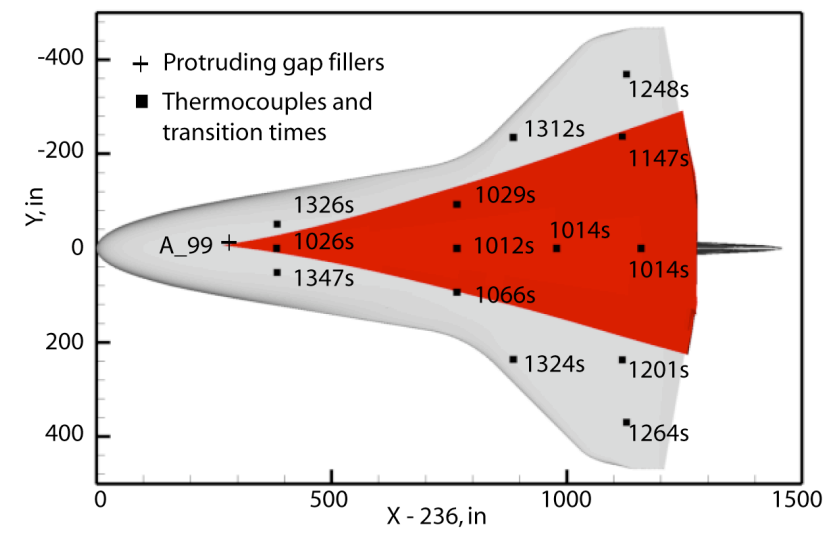

Figure 9. STS-99 Thermocouple transition times and predicted paths of turbulent wedges from damage sites.

Table 5. Gap filler location for STS-99.

\begin{tabular}{|c|c|c|c|c|c|}
\hline Gap Filler & $X-236 .$, in & $Y$, in & $Z$, in & $\mathrm{k}$, in & Source \\
\hline A 99 & 267.5 & -6.4 & 278.8 & 0.35 & TPSPFA,QLR \\
\hline
\end{tabular}

Table 6. STS-99 Comparison of transition times.

\begin{tabular}{|c|c|c|c|c|}
\hline Gap Filler & \begin{tabular}{||l} 
Predicted \\
Transition \\
Time, s (BLT Tool) \\
\end{tabular} & \begin{tabular}{|l} 
Actual \\
Transition \\
Time,s \\
(Thermocouple) \\
\end{tabular} & $\begin{array}{l}\text { Predicted } \\
\text { Mach Number } \\
\text { (BLT Tool) } \\
\end{array}$ & \begin{tabular}{|l} 
Actual \\
Transition \\
Mach Number \\
(Nav)
\end{tabular} \\
\hline A 99 & 994. & 1012. & 16.5 & 16.9 \\
\hline
\end{tabular}




\section{STS-1}

The historic first flight of the orbiter Columbia occurred 25 years ago on April 12, 1981 with a landing on April 14, 1981 at Edwards Air Force Base in California. For flights STS-1 to STS-5 the orbiter was instrumented with thermocouples as shown in Fig. 10. Unfortunately, for flight STS-1, the thermocouple data was only recorded for $t>1050 \mathrm{~s}$ after entry interface due to equipment malfunctions. A plot of the output of selected thermocouples is shown in Fig. 11. The best we can estimate from the thermocouple data is that transition occurred prior to $t$ $=1050$ s for the thermocouples that show no evidence of transition at all. In an examination of orbiter heating data, Harthun, et al. ${ }^{7}$ predicted the time of transition from axial force data and elevon asymmetry to be $\mathrm{t} \sim 1000 \mathrm{~s}$. Bouslog, et al. $^{23}$ in an analysis of early flight data computed the axial force coefficient for the orbiter and found a correlation between it and the time of transition as deduced from the thermocouples. From this analysis they estimated the time of transition from STS-1 at $\mathrm{t} \sim 1025 \mathrm{~s}$.

Because this flight occurred so long ago it has been difficult to find details of the damage to the orbiter. There are no QLR or DIT reports and no entries in the $\mathrm{KSC}$ IPR/PR/DR database. The only significant damage to be a possible source of early transition is a particularly large cavity, Fig. 12 photo (NASA Photo S81-30555) that occurred on the right Nose Landing Gear Door (NLGD). For many years it has been assumed that the early transition detected on the flight STS-1 was solely due to the NLGD cavity. In fact, this damage is the only low Reynolds number, high Mach number cavity site that has been found to date for any of the orbiters and was counted as such in the analysis that was done prior to RTF for STS-114. While reanalyzing the cavity site for this report, we noticed that gap filler was located in the cavity and was potentially protruding above the surface. An indepth search of the photo archive by engineers at Johnson Space Center resulted in the discovery of three side views of the cavity and the associated gap filler. One of these views is shown on in Fig. 13 (NASA Photo S81-30890). While these additional views of the cavity do not provide conclusive evidence, it is now considered highly likely that the gap filler was sticking out. From the photos, it appears that the gap filler is extending into the cavity formed in the tile. The tile with the major portion of damage is identified as V070-391040-038. ${ }^{29}$ This tile was eventually replaced by tile V070-391040-240 and that tile's coordinates were used for the location of the cavity. The gap filler in question was located between tiles V070-391042-020 and V070-391026-027 (or their modern equivalents). The location and

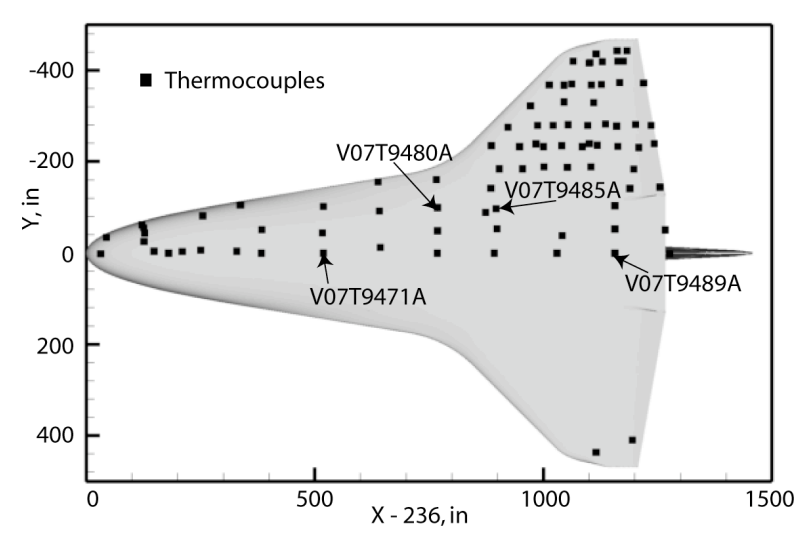

Figure 10. Thermocouple locations for STS-1.

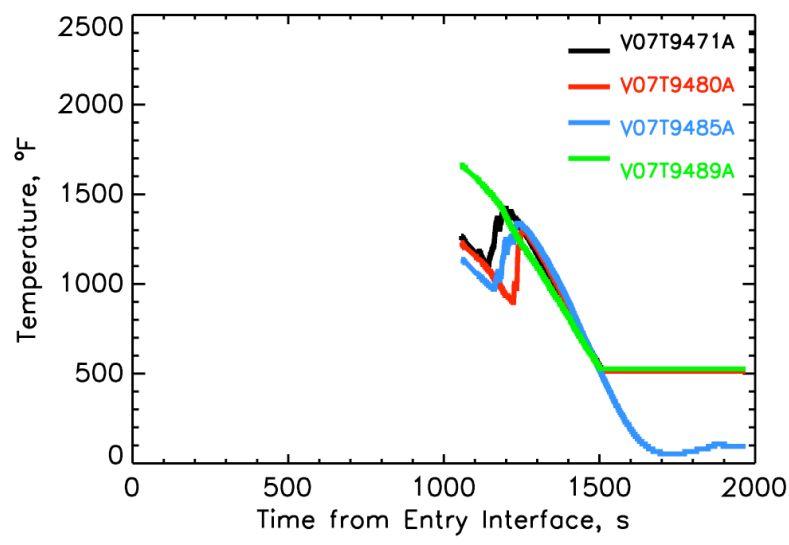

Figure 11. Thermocouple traces for STS-1.

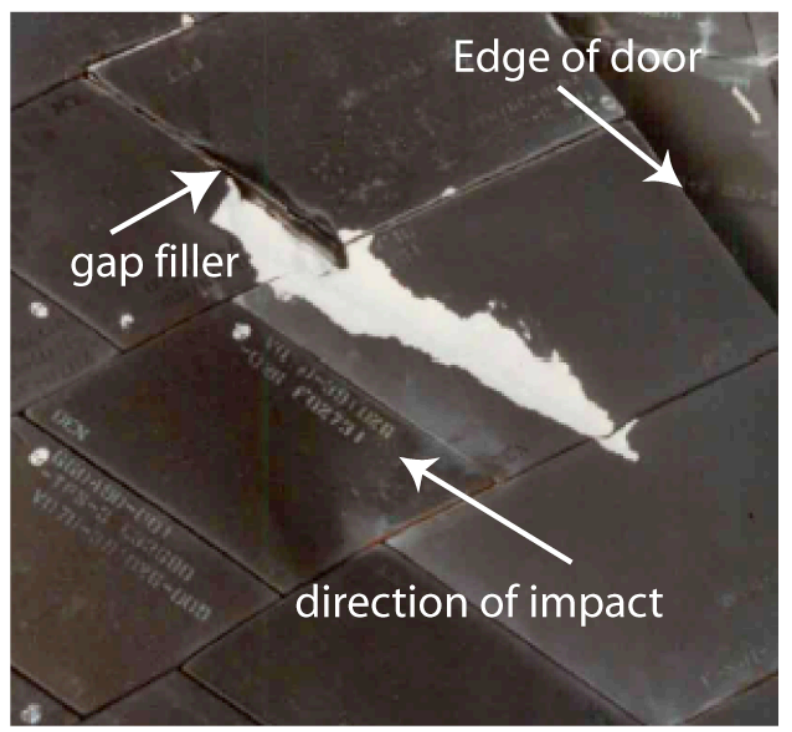

Figure 12. STS-1, NLGD cavity and gap filler.

10

American Institute of Aeronautics and Astronautics 
dimensions of the cavity are given in Table 7 and the location of the gap filler is given in Table 8 .

Once it was established that the gap filler might have been protruding into the flow, we tried to estimate the amount that it may have been protruding. In Ref. 29 a photograph of the gap filler is presented alongside of a ruler. This photo and its description, along with the other photos led us to estimate that the maximum height for the portion of the gap filler that was exposed in the cavity was approximately 0.56 inches. However, not all of this portion of the gap filler would be protruding above the OML of the orbiter. To bound the possible size of the gap filler we can estimate the size a protruding gap filler at the specified location would need to be in order to cause transition at the time observed by the flight data. If we assume that transition occurred sometime during $1000 \mathrm{~s}<\mathrm{t}<1050$ s and use the output of the BLT Tool,

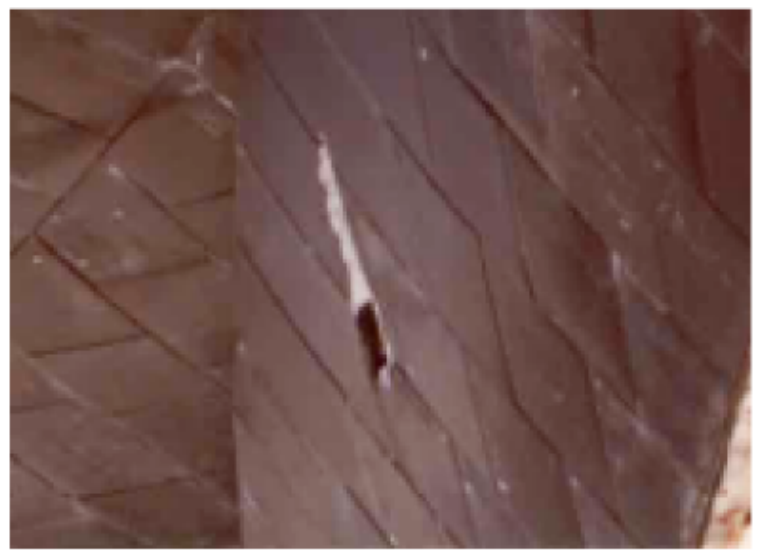
a gap filler protruding in the range $0.18 \mathrm{in}<\mathrm{k}<0.26$ in

Figure 13. Side view of gap filler, STS-1. would be sufficient to trip the boundary layer at this location. Based on our analysis it is probable, though inconclusive, that the gap filler height was at least one source of transition. In Fig. 14, we show the location of the gap filler as between the tiles with the circles. In the figure, an arrow represents the flow on the orbiter at this point. Here we see that the flow would be directly impacting the gap filler in this configuration. Furthermore, the wind tunnel research that the boundary layer transition prediction is based on only studied the effects of protuberances and cavities separately. Therefore, we do not know the possible interaction effects that may exist due to the combination of a gap filler and large cavity.

The predicted paths for the cavity and the gap filler are shown in Fig. 15. For this plot we have indicated the transition times of only a few of the thermocouples. The rest are divided into three groups, the red symbols indicate that transition occurred prior to $\mathrm{t}=1050 \mathrm{~s}$, the yellow symbols indicate that transition occurred between $1050 \mathrm{~s}<\mathrm{t}<$ $1200 \mathrm{~s}$, and the green symbols indicate that transition occurred at $\mathrm{t}>1200 \mathrm{~s}$. Black symbols are non-functioning sensors. Clearly the position of the gap filler and the cavity both account for the earliest transition times. Also note that even though the gap filler (magenta) and cavity (blue) location are in very close proximity, the paths predicted by the Wedge Tool are slightly different. This suggests that, at least for sites close to the nose, the Wedge Tool should be run for points encompassing the extent of the damage in the Y direction rather than a point in order to predict the possible extent of transition. The predicted transition times for the cavity are listed in Table 9; the predicted times are close to the times suggested by the axial force analysis of Ref. 7. In our analysis, we use length as the value given by the long dimension of the cavity, and for many sites we were are unable to determine the orientation of the cavity with respect to the flow. In this case we know that the cavity is not aligned perfectly with

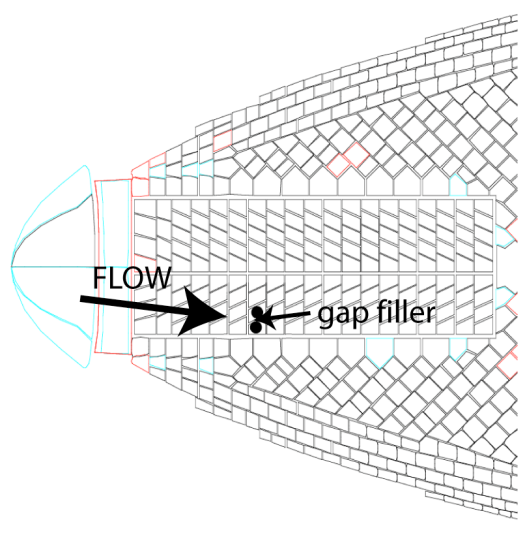

Figure 14. Sketch of STS-1 gap filler location and approximate flow direction.

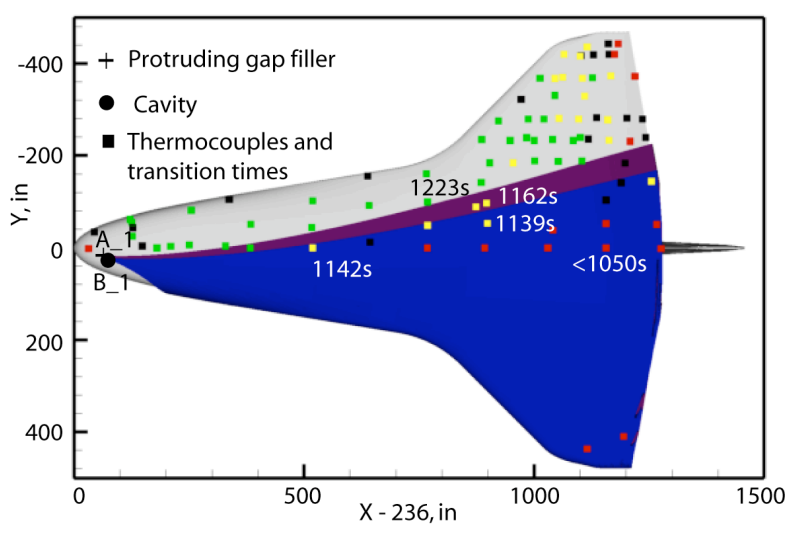

Figure 15. STS-1 Thermocouple transition times and predicted paths of turbulent wedges from damage sites. 
the flow and obviously the choice of length affects the predicted result. Better documentation of cavity alignment would alleviate this problem.

Table 7. Cavity location STS-1.

\begin{tabular}{|l||l||l|l||l|l|l|l||}
\hline \hline Cavity & X-236., in & Y, in & Z, in & L, in & W,in & D,in & Source \\
\hline B_1 & 68.6 & 18.3 & 299.1 & 10 & 0.7 & 1 & Ref. 28 \\
\hline
\end{tabular}

Table 8. Gap filler location STS-1.

\begin{tabular}{|c|c|c|c|c|c|}
\hline Gap Filler & $\mathrm{X}-236 .$, in & $\mathrm{Y, \text {in }}$ & $Z$, in & $\mathrm{k}$, in & Source \\
\hline A_1 & 74.31 & 15.98 & 291.3 & NA & Ref.28 \\
\hline
\end{tabular}

Table 9. STS-1 Comparison of transition times.

\begin{tabular}{|l|l|l|l|l||l|l||}
\hline & $\begin{array}{l}\text { Length } \\
\text { Predicted } \\
\text { Transition } \\
\text { Time, } \mathrm{s}\end{array}$ & $\begin{array}{l}\text { Depth } \\
\text { Predicted } \\
\text { Transition } \\
\text { Time, } \mathrm{s}\end{array}$ & $\begin{array}{l}\text { Actual } \\
\text { Transition } \\
\text { Time, } \mathrm{s} \\
\text { Cavity }\end{array}$ & $\begin{array}{l}\text { Length } \\
\text { Predicted } \\
\text { Transition } \\
\text { Mach Number }\end{array}$ & $\begin{array}{l}\text { Depth } \\
\text { Predicted } \\
\text { Transition } \\
\text { Mach Number }\end{array}$ & $\begin{array}{l}\text { Actual } \\
\text { Transition } \\
\text { Mach Number } \\
\text { (Nav) }\end{array}$ \\
\hline B_1 & 974. & 996. & $1000<\mathrm{t}<1050$ & 16.2 & 15.5 & $16.0<\mathrm{M}<14.5$ \\
\hline
\end{tabular}

\section{E. STS-41}

STS-41 was the $11^{\text {th }}$ flight of the orbiter Discovery (OV103) and landed at Edwards Air Force Base in California on October 6, 1990. The orientation and names for the thermocouples for the orbiter Discovery are shown in Fig. 16. The thermocouple traces for the four thermocouples that were working for this flight are shown in are shown in Fig. 17. For this flight thermocouple V07T9468A returned no data. Transition occurred first for V07T9711A, the thermocouple outboard on the left wing tip, and then occurred only several seconds later for the remaining three thermocouples. These times are all above $\mathrm{t}=$ 1200 s and as such are very close to the normally occurring transition times for the orbiters without damage.

For the analysis prior to STS-114, STS-41 was considered a cavity case. In our review of the data we found that the TPSPFA report ${ }^{30}$ listed two cavities of

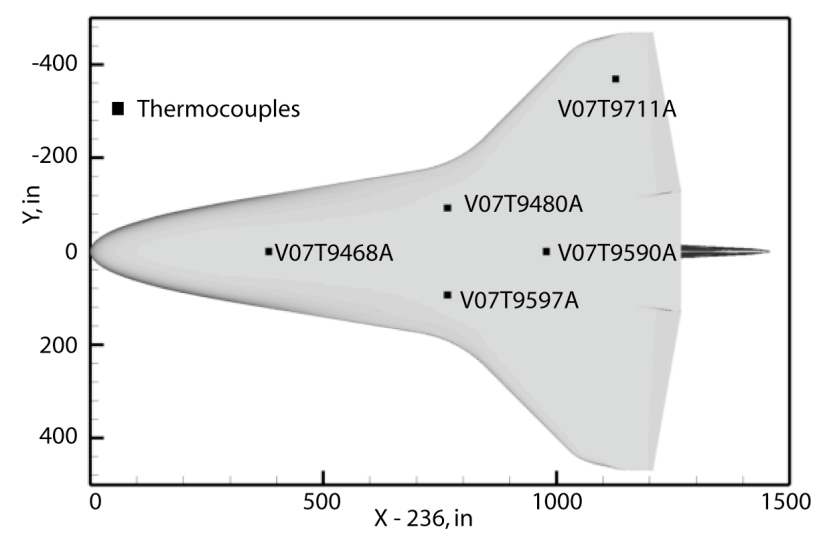

Figure 16. Thermocouple names and locations for Discovery. significant size and listed the affected tiles and dimensions. The first was a rather large cavity on the left hand chine and the second was a smaller cavity located on the right hand side of the orbiter close to thermocouple V07T9597. Although large, the cavity on the left hand chine did not affect the lower surface of the orbiter because it was outside the attachment line and therefore its influence was swept up to the upper fuselage. The DIT report ${ }^{31}$ and data from the KSC IPR/PR/DR database returned a list of potential cavity sites. For cavity A_41, the TPSPFA report listed the site as 4 in $x 1$ in $x$. 0.4 in, the KSC IPR/PR/DR database listed the damage separately on two different tiles as $3.7 \times 1.9 \times .32$ and $1.4 \times .7 \times .4$, and the DIT report listed the site as $4 \times 2 \times 0.375$. For this instance, the descriptions were remarkably close. Unfortunately, this is not always the case, and without the knowledge that the cavity spanned the two tiles we would not be able to reconstruct it in the KSC IPR/PR/DR database. The second cavity was found in the KSC IPR/PR/DR database and the DIT report. It was listed as $2.1 \times 0.55 \times 0.1$ in the first and as $2.5 \times 0.375 \times .125$ in the latter. There was also a larger cavity noted on the DIT damage map, but it was not mentioned in the TPSPFA or found in KSC IPR/PR/DR. During the STS-114 analysis it was noted that the DIT team sometimes grouped together damage sites into one measurement. Since this team is primarily concerned with discovering the cause of damage and documenting the 
extent this type of cataloging is understandable. It does, however, add to the difficulty of sorting and finding damage. In this instance, the cavity site did not influence any of the thermocouples so it is not used in this analysis.

A search of the KSC IPR/PR/DR database also returned 19 protruding gap fillers, although many were below 0.1in. Due to the late transition time, even a small gap filler protrusion could be the source of transition and may be easily overlooked by the TPSPSA and the QLR reports. According to the KSC IPR/PR/DR database, the gap filler was entered into the system after the shuttle was ferried back to KSC. However, paper reports were generated at Edwards and later entered into the system. At this point, we must assume the gap filler was due to flight damage until otherwise proved.

Once all of the damage data were collected they were run through the BLT Tool to determine which damage/protrusion sites were sufficient to cause transition in the time measured by the thermocouples. The sites that were found to be likely to cause transition were then run through the Wedge Tool. In addition to the two cavities (Table 10) tracked in the analysis to support STS-114, and one new gap filler (Table 11) was predicted to cause early transition and influence the thermocouple readings. The paths for the two cavities and the gap filler are shown in Fig. 18. The inboard region of influence for the gap filler C_41 is very close to the region of influence for the cavity A_41. The cavity site B_41 does not appear to have influenced any of thermocouples. A comparison of the predicted transition times and the transition times as indicated by the thermocouples are presented in Tables 12 and 13. The transition times predicted for the depth of cavity A_41 and for height of gap filler C_41 both compare well with the transition time predicted by the thermocouples, thus making it impossible to assign cause to either one. Unfortunately, the majority of cavity cases found so far are for transition times on the order of STS-41. Given that this time is already so close to the normal transition time of the orbiter and that even small protrusions of gap fillers can be responsible for transition, all of the low Mach number transition cases should be reexamined for the possibility of protruding gap fillers.

Table 10. Cavity locations for STS-41.

\begin{tabular}{|c|c|c|c|c|c|c|c|}
\hline Cavity & $\mathrm{X}-236$. , in & $\mathrm{Y}$, in & $Z$, in & $\mathrm{L}$, in & $\mathrm{W}$,in & $\mathrm{D}$,in & Source \\
\hline A 41 & $\mid 379.9$ & $\mid-21.2$ & 276.7 & 4.1 & 1.9 & 0.4 & $\begin{array}{l}\text { KSC IPR/PR/DR, TPSPFA, } \\
\text { DIT }\end{array}$ \\
\hline B 41 & 753.3 & 106.1 & 274.1 & 2.1 & 0.55 & 0.1 & KSC IPR/PR/DR \\
\hline
\end{tabular}

Table 11. Gap filler location for STS-41.

\begin{tabular}{|c|c|c|c|c|c|}
\hline Gap Filler & $X-236 .$, in & $\mathrm{Y}$, in & $Z$, in & $\mathrm{k}$, in & Source \\
\hline C 41 & 274.9 & -45.6 & 281.6 & 0.11 & KSC IPR/PR/DR \\
\hline
\end{tabular}


Table 12. Comparison of transition times for cavities for STS-41.

\begin{tabular}{|l||l||l|l|l|l|l||}
\hline & $\begin{array}{l}\text { Length } \\
\text { Predicted } \\
\text { Transition } \\
\text { Time, } \mathrm{s}\end{array}$ & $\begin{array}{l}\text { Depth } \\
\text { Predicted } \\
\text { Transition } \\
\text { Time, } \mathrm{s}\end{array}$ & $\begin{array}{l}\text { Actual } \\
\text { Transition } \\
\text { Time, } \mathrm{s} \\
\text { (Thermocouple) }\end{array}$ & $\begin{array}{l}\text { Length } \\
\text { Predicted } \\
\text { Transition } \\
\text { Mach Number }\end{array}$ & $\begin{array}{l}\text { Depth } \\
\text { Predicted } \\
\text { Transition } \\
\text { Mach Number }\end{array}$ & $\begin{array}{l}\text { Actual } \\
\text { Transition } \\
\text { Mach Number } \\
\text { (Nav) }\end{array}$ \\
\hline A 41 & 1114. & 1215 & 9.8 & 8.2 & 7.9 \\
\hline B 41 & 1212. & 1342. & N/A & 7.1 & 6.0 & N/A \\
\hline
\end{tabular}

Table 13. Comparison of transition times for the gap filler for STS-41.

\begin{tabular}{|c|c|c|c|c|}
\hline Gap Filler & \begin{tabular}{|l} 
Predicted \\
Transition \\
Time, s (BLT Tool)
\end{tabular} & $\begin{array}{l}\text { Actual } \\
\text { Transition } \\
\text { Time, s } \\
(\text { Thermocouple) }\end{array}$ & \begin{tabular}{|l} 
Predicted \\
Mach Number \\
(BLT Tool)
\end{tabular} & $\begin{array}{l}\text { Actual } \\
\text { Transition } \\
\text { Mach Number } \\
\text { (Nav) }\end{array}$ \\
\hline C 41 & 1176. & 1201. & 7.96 & 7.9 \\
\hline
\end{tabular}

\section{Summary}

In support of the continuing Return to Flight effort we have begun an in-depth reanalysis of the flight cases that were used to validate the tools designed to predict early orbiter boundary layer transition due to protrusions/damage as it reenters the atmosphere. In reviewing the data, we analyzed damage information from multiple sources. During the course of our investigation we found that the damage sources available did not completely describe the damage sites and that information had to be pieced together from several sources. This is in part because none of our sources are solely focused on providing data for boundary layer transition prediction purposes. In order to improve our tools, we need accurate locations and dimensions for the gap fillers and cavities. We recommend the following for future documentation of flight damage.

For gap fillers:

a. The gap filler height (or heights if tapered) and angle (if bent over) must be measured both in orbit and on the ground.

b. Photos should be taken of all protruding gap fillers, front, side, and above (to include tile numbers so that the orientation of the gap filler with respect the flow can be determined).

For cavities:

a. Large cavities should be laser scanned so that an accurate volume can be calculated. If this is not possible, more detailed dimensions should be provided on a sketch.

b. Photos should be taken of cavities from directly above and should include tile numbers

c. When recording cavity information in the KSC IPR/PR/DR database, if the damage extends to another tile it should be noted in the record along with the original cavity dimensions

d. To reduce the amount of time to search the KSC IPR/PR/DR database, it would be helpful if protruding gap fillers and cavities were logged in with consistent How Malfunctioned codes.

e. When preparing the DIT damage map, if any sites are grouped together that information should be indicated.

We would like to acknowledge that even though we found deficiencies if the reporting of damage sites, considering the scope of the vehicle TPS, the extent of the documentation is impressive. However, given the serious nature of requiring an on orbit repair, it seems reasonable that for the remainder of the shuttle flights extra attention be given the documentation of damage with respect to the problem of boundary layer transition.

For the first three flights presented, STS-28R, STS-55, and STS-99 we found that the protruding gap fillers provided reasonable explanations for the transition times computed from the thermocouple traces. Several thermocouple traces from flight STS-28 and STS-55 showed anomalous behavior that may be related to the vehicle flight parameters, but further study of this phenomena is necessary before we can conclusively explain the dependence. 
The latter two cases presented, STS-1 and STS-41, were originally treated as cavity cases for the analysis supporting STS-114. For STS-1 the large cavity near the nose of the orbiter is the only high Reynolds number case available for validation of the choice of the parameter $\mathrm{C}$ in equation 1. Although the cavity is a reasonable source for the early transition that occurred on STS-1, our reanalysis of the documentation available indicated that gap filler was protruding at the cavity site. We could not determine the height of the gap filler protrusion, but based on the prediction using equation 1 we found that a protrusion of as little as $k=0.18 \mathrm{in}$. could also account for the early transition. Given that the gap filler and the cavity are collocated, it would be helpful to have wind tunnel tests that combine the two possible scenarios. For flight STS-41, we also found a gap filler could be the cause of the transition time observed. For these reasons, STS-41 should not be used as a validation case unless evidence can be found that eliminates the gap filler as a source. The results of the STS-41 analysis indicate that all of the low Mach number cases that were previously assumed to be cavity cases should be reexamined for the possibility of gap filler protrusions. Also, the remaining flight data must be analyzed in order to find any cavity cases that may be applicable to the validation effort.

\section{Acknowledgments}

Author C.B. McGinley would like to thank David Bretz for photographic analysis and helpful discussions on STS-1 and other flights, Cooper Snap for searching for photos of STS-1 and helping to interpret them, Margaret Guardia for helping to get access to the KSC IPR/PR/DR and other sources, Jenny Tran and Anita Pinkosky for tracking numerous historical tile numbers, Paul Hosking and Mike Powell for working complicated and time consuming firewall issues, Mark Bray for his help in understanding the KSC IPR/PR/DR database, and Armando Oliu for his help in understanding the Debris/Ice Team reports.

\section{References}

${ }^{1}$ Report of the Columbia Accident Investigation Board. Government Printing Office, Washington, D.C. August 2003.

2 Hale, W.N., Lamotte, N.O., and Garner, T.W., "Operational Experience with Hypersonic Flight of the Space Shuttle”, AIAA Paper 2002-5259, Oct. 2002.

3 Ried, R. C., Goodrich, W. D., Strouhal, G., and Curry, D. M., "The Importance of Boundary-Layer Transition to the Space Shuttle Design," Proceedings of the Boundary-Layer Transition Workshop held Nov. 3-5, 1971, Aerospace Corp. Report No. TOR_0172(S2816-16) -5, Dec. 20, 1971.

4 Lee, D. B., and Harthun, M. H., “Aerothermodynamic Entry Environment of the Space Shuttle Orbiter,” AIAA Paper 82-0821, June 1982.

5 Haney, J. W., “Orbiter (Pre STS-1) Aeroheating Design Data Base Development Methodology: Comparison of Wind Tunnel and Flight Test Data," NASA CP-3248, Orbiter Experiments (OEX) Aerothermodynamics Symposium, April 1995, pp. 607-675.

6 Goodrich, W. D., Derry, S. M., and Bertin, J. J., "Shuttle Orbiter Boundary Layer Transition at Flight and Wind Tunnel Conditions," Shuttle Performance: Lessons Learned, Part 2, NASA CP 2283, March 1983, pp. 753-779.

7 Harthun, M. H., Blumer, C.B., and Miller, B. A., "Orbiter Windward Surface Entry Heating: Post-Orbital Flight Test Program Update," Shuttle Performance: Lessons Learned, Part 2, NASA CP 2283, March 1983, pp. 781-804.

8 Poll, D. I. A., "Boundary Layer Transition on the Windward Face of Space Shuttle During Re-Entry," AIAA Paper 85-0899, June 1985.

9 Hartung, L. C., and Throckmorton, D. A., "Computer Visualization of Orbiter Lower Surface Boundary-Layer Transition," Journal of Spacecraft and Rockets, Vol. 24, No. 2, March-April 1987, pp. 109-114.

${ }^{10}$ Hartung, L. C., and Throckmorton, D. A., "Space Shuttle Entry Heating Data Book, Volumes I-III," NASA RP 1191-1193, May 1988.

11 Bouslog, S. A., An, M. Y., and Derry, S. M., “Orbiter Windward Surface Boundary Layer Transition Flight Data,” NASA CP3248, Orbiter Experiments (OEX) Aerothermodynamics Symposium, April 1995, pp. 703-739.

12 An, M. Y., Wang, K. C., Campbell, C. H., and Pelley, R. L., "Space Shuttle Orbiter Aerodynamics Induced by Asymmetric Boundary-Layer Transition,” AIAA Paper 96-0808, Jan. 1996.

13 Bouslog, S. A., Bertin, J. J., Berry, S. A., and Caram, J. M., "Isolated Roughness Induced Boundary-Layer Transition: Shuttle Orbiter Ground Tests and Flight Experience," AIAA Paper 97-0274, Jan. 1997.

14 Campbell, C.H., et al., Orbiter Return-to-Flight Entry Aeroheating, AIAA Paper 2006-2197, June 2006.

15 Berry, S. A., Horvath, T.J, Greene, F., Kinder, G. R., Wang, K. C., Overview of Boundary Layer Transition Research in Support of Orbiter Return to Flight, AIAA Paer 2006-2198, June 2006. 
${ }^{16}$ Horvath, T. J., Berry, S. A., Merski, N. R., Berger, K. T., Liechty, D.S., and Schneider, S. P., Shuttle Damage/Repair from the Perspective of Hypersonic Boundary Layer Transition - Experimental Results, AIAA Paper 2006-2919, June 2006.

17 Greene, F., Hamilton, H., and Weilmuenster, K. J., "Development of a Boundary Layer Properties Interpolation Tool in Support of Orbiter Return-To-Flight,” AIAA Paper 2006-2918, June, 2006.

18 Berry, S. A., Horvath, T. J., Cassady, A., Kirk, B. J., Wang, K.C., Hyatt, A., Boundary Layer Transition Results From STS114, AIAA Paper 206-2922, June, 2006.

19 McNeil Cheatwood, F. and Gnoffo, P. A., User's Manual for the Langley Aerothermodynamic Upwind Relaxation Algorithm, NASA TM 4674, April, 1996.

20 Wright, M. J., and Candler, G. V., A Data-Parallel Relaxation Method for the Navier-Stokes Equations, AIAA Paper 97-2046, June, 1997.

21 Fischer, M. C., Spreading of a Turbulent Disturbance, AIAA Journal, Vol. 10, No. 7, 1972, pp 957-959.

22 Robertson, J., Mission STS-28R OV102 Flight 8 Thermal Protection System Post Flight Assessment, KLO-89-004, Rockwell International Corporation, Contract NAS9-14000.

23 Bouslog, S. A., An, M. Y., Hartman, L. N., Review of Boundary Layer Transition Flight Data on the Space Shuttle Orbiter, AIAA Paper 91-0741, Jan. 1991.

24 Green, M. J., Budnick, M. P., Yang, L., and Chiasson, M. P., Supporting Flight Data Analysis for the Space Shuttle Orbiter Experiments at NASA Ames Research Center, AIAA Paper 83-1532, June, 1983.

25 Stevenson, C. G., Katnik, G. N., and Higginbotham, S. A., Debris/Ice/TPS Assessment and Photographic Analysis for Shuttle Mission STS-28R, NASA TM 102152, Sept. 1989.

${ }^{26}$ Kinder, G. R., STS-28 Protruding Gap Filler Locations, SJ00-SJC0D-2004-030, The Boeing Company, 2004.

27 Grant, G., Mission STS-55 OV102 Flight 14 Thermal Protection System Post Flight Assessment, KLO-93-007, Rockwell International Corporation, Contract NAS9-18400, Sept., 1993.

${ }^{28}$ Hooks, M., Mission STS-99 OV105 Flight 14 Thermal Protection System Post Flight Assessment, KLO-00-004, The Boeing Company, Oct. 2000.

29 Mitchell, S. M., Orbiter STS-1 Thermal Protection System, Post Flight Analysis - Interim Report, LTR-1225-4570, Rockwell International, May, 1981.

30 Cipolletti, J., Mission STS-41 OV103 Flight 11 Thermal Protection System Post Flight Assessment, KLO-90-008, Contract NAS9-18400, Rockwell International Corporation, Dec. 1990.

31 Katnik, G. N., Higginbotham, S.A., Davis, J.B., Debris/Ice/TPS Assessment and Photographic Analysis for Shuttle Mission STS-41, NASA TM-103814, June, 1990. 